\title{
Hybrid algorithms for equilibrium and common fixed point problems with applications
}

\author{
Qingnian Zhang ${ }^{1 *}$ and Huilian $\mathrm{Wu}^{2}$
}

\section{"Correspondence:}

wszhangqn@yeah.net

${ }^{1}$ School of Mathematics and

Information Science, North China

University of Water Resources and

Electric Power, Zhengzhou, 450011,

China

Full list of author information is

available at the end of the article

\begin{abstract}
In this paper, hybrid algorithms are investigated for equilibrium and common fixed point problems. Strong convergence of the algorithms is obtained in the framework of reflexive Banach spaces.
\end{abstract}

Keywords: asymptotically quasi- $\phi$-nonexpansive mapping; quasi- $\phi$-nonexpansive mapping; algorithm; equilibrium problem; fixed point

\section{Introduction}

Iterative algorithms have emerged as an effective and powerful tool for studying a wide class of problems which arise in economics, finance, image reconstruction, ecology, transportation, network, elasticity and optimization; see [1-11] and the references therein. The computation of solutions of nonlinear operator equations (inequalities) is important in the study of many real-world problems. Recently, the study of the convergence of various iterative algorithms for solving various nonlinear mathematical models has formed a major part of numerical mathematics. Among these iterative algorithms, the KrasnoselskiMann iterative algorithm and the Ishikawa iterative algorithm are popular and much discussed. It is well known that both the Krasnoselski-Mann iterative algorithm and the Ishikawa iterative algorithm only have weak convergence even for nonexpansive mappings in infinite-dimensional Hilbert spaces. In many disciplines, including economics, image recovery, quantum physics, and control theory, problems arise in infinite-dimensional spaces. In such problems, strong convergence is often much more desirable than weak convergence. To improve the weak convergence of the Krasnoselski-Mann iterative algorithm and the Ishikawa iterative algorithm, so-called projection algorithms have been investigated in different frameworks of spaces; see [12-26] and the references therein.

The aim of this article is to investigate solutions of equilibrium and common fixed point problems in Hilbert spaces. In Section 2, we provide some necessary preliminaries. In Section 3, a projection algorithm is investigated. Strong convergence of the algorithm is obtained in a uniformly smooth and strictly convex Banach space which also has the Kadec-Klee property. In Section 4, applications are provided to support the main results of this paper.

O2014 Zhang and Wu; licensee Springer. This is an Open Access article distributed under the terms of the Creative Commons Attribution License (http://creativecommons.org/licenses/by/2.0), which permits unrestricted use, distribution, and reproduction in any medium, provided the original work is properly cited. 


\section{Preliminaries}

Let $E$ be a real Banach space with the dual $E^{*}$. Recall that the normalized duality mapping $J$ from $E$ to $2^{E^{*}}$ is defined by $J x=\left\{f^{*} \in E^{*}:\left\langle x, f^{*}\right\rangle=\|x\|^{2}=\left\|f^{*}\right\|^{2}\right\}$, where $\langle\cdot, \cdot\rangle$ denotes the generalized duality pairing. Let $U_{E}=\{x \in E:\|x\|=1\}$ be the unit sphere of $E$. $E$ is said to be smooth iff $\lim _{t \rightarrow 0} \frac{\|x+t y\|-\|x\|}{t}$ exists for each $x, y \in U_{E}$. It is also said to be uniformly smooth iff the above limit is attained uniformly for $x, y \in U_{E}$. $E$ is said to be strictly convex iff $\left\|\frac{x+y}{2}\right\|<1$ for all $x, y \in E$ with $\|x\|=\|y\|=1$ and $x \neq y$. It is said to be uniformly convex iff $\lim _{n \rightarrow \infty}\left\|x_{n}-y_{n}\right\|=0$ for any two sequences $\left\{x_{n}\right\}$ and $\left\{y_{n}\right\}$ in $E$ such that $\left\|x_{n}\right\|=\left\|y_{n}\right\|=1$ and $\lim _{n \rightarrow \infty}\left\|\frac{x_{n}+y_{n}}{2}\right\|=1$. It is well known that if $E$ is uniformly smooth, then $J$ is uniformly norm-to-norm continuous on each bounded subset of $E$. It is also well known that if $E$ is (uniformly) smooth if and only if $E^{*}$ is (uniformly) convex.

In what follows, we use $\rightarrow$ and $\rightarrow$ to stand for the weak and strong convergence, respectively. Recall that a space $E$ has the Kadec-Klee property iff for any sequence $\left\{x_{n}\right\} \subset E$, $x \in E$ with $x_{n} \rightarrow x$, and $\left\|x_{n}\right\| \rightarrow\|x\|$, we have $\left\|x_{n}-x\right\| \rightarrow 0$ as $n \rightarrow \infty$. It is known that if $E$ is a uniformly convex Banach spaces, then $E$ has the Kadec-Klee property.

Let $E$ be a smooth Banach space. Let us consider the functional defined by $\phi(x, y)=$ $\|x\|^{2}-2\langle x, J y\rangle+\|y\|^{2}, \forall x, y \in E$. Observe that, in a Hilbert space $H$, the equality is reduced to $\phi(x, y)=\|x-y\|^{2}, x, y \in H$. As we know, if $C$ is a nonempty, closed, and convex subset of a Hilbert space $H$ and $P_{C}: H \rightarrow C$ is the metric projection of $H$ onto $C$, then $P_{C}$ is nonexpansive. This fact actually characterizes Hilbert spaces, and consequently it is not available in more general Banach spaces. In this connection, Alber [27] recently introduced a generalized projection operator $\Pi_{C}$ in a Banach space $E$ which is an analog of the metric projection $P_{C}$ in Hilbert spaces. Recall that the generalized projection $\Pi_{C}: E \rightarrow C$ is a map that assigns to an arbitrary point $x \in E$ the minimum point of the functional $\phi(x, y)$, that is, $\Pi_{C} x=\bar{x}$, where $\bar{x}$ is the solution to the minimization problem $\phi(\bar{x}, x)=\min _{y \in C} \phi(y, x)$. Existence and uniqueness of the operator $\Pi_{C}$ follow from the properties of the functional $\phi(x, y)$ and strict monotonicity of the mapping $J$. If $E$ is a reflexive, strictly convex, and smooth Banach space, then $\phi(x, y)=0$ if and only if $x=y$; for more details, see [27] and the references therein. In Hilbert spaces, $\Pi_{C}=P_{C}$. From the definition of the function $\phi$, we also have

$$
(\|x\|-\|y\|)^{2} \leq \phi(x, y) \leq(\|y\|+\|x\|)^{2}, \quad \forall x, y \in E
$$

and

$$
(\|x\|-\|y\|)^{2} \leq \phi(x, y) \leq(\|y\|+\|x\|)^{2}, \quad \forall x, y \in E .
$$

Let $F$ be a bifunction from $C \times C$ to $\mathbb{R}$, where $\mathbb{R}$ denotes the set of real numbers. Recall the following equilibrium problem. Find $p \in C$ such that $F(p, y) \geq 0, \forall y \in C$. We use $E P(F)$ to denote the solution set of the equilibrium problem. Numerous problems in physics, optimization and economics reduce to finding a solution of the equilibrium problem.

Next, we give the following assumptions:

(A1) $F(x, x)=0, \forall x \in C$;

(A2) $F$ is monotone, i.e., $F(x, y)+F(y, x) \leq 0, \forall x, y \in C$;

(A3) $\lim \sup _{t \downarrow 0} F(t z+(1-t) x, y) \leq F(x, y), \forall x, y, z \in C$;

(A4) for each $x \in C, y \mapsto F(x, y)$ is convex and weakly lower semi-continuous. 
Let $C$ be a nonempty subset of $E$ and let $T: C \rightarrow C$ be a mapping. In this paper, we use $F(T)$ to stand for the fixed point set of $T$. Recall that $T$ is said to be asymptotically regular on $C$ iff for any bounded subset $K$ of $C, \lim _{\sup _{n \rightarrow \infty}}\left\{\left\|T^{n+1} x-T^{n} x\right\|: x \in K\right\}=0$. Recall that $T$ is said to be closed iff for any sequence $\left\{x_{n}\right\} \subset C$ such that $\lim _{n \rightarrow \infty} x_{n}=x_{0}$ and $\lim _{n \rightarrow \infty} T x_{n}=y_{0}$, then $T x_{0}=y_{0}$. Recall that a point $p$ in $C$ is said to be an asymptotic fixed point of $T$ iff $C$ contains a sequence $\left\{x_{n}\right\}$ which converges weakly to $p$ such that $\lim _{n \rightarrow \infty}\left\|x_{n}-T x_{n}\right\|=0$. The set of asymptotic fixed points of $T$ will be denoted by $\widetilde{F}(T)$. $T$ is said to be relatively nonexpansive iff $\widetilde{F}(T)=F(T) \neq \emptyset$ and

$$
\phi(p, T x) \leq \phi(p, x), \quad \forall x \in C, \forall p \in F(T) .
$$

$T$ is said to be relatively asymptotically nonexpansive iff $\widetilde{F}(T)=F(T) \neq \emptyset$ and

$$
\phi\left(p, T^{n} x\right) \leq\left(1+\mu_{n}\right) \phi(p, x), \quad \forall x \in C, \forall p \in F(T), \forall n \geq 1,
$$

where $\left\{\mu_{n}\right\} \subset[0, \infty)$ is a sequence such that $\mu_{n} \rightarrow 0$ as $n \rightarrow \infty$.

Remark 2.1 The class of relatively asymptotically nonexpansive mappings, which is an extension of the class of relatively nonexpansive mappings, was first introduced in [28].

Recall that $T$ is said to be quasi- $\phi$-nonexpansive iff $F(T) \neq \emptyset$ and

$$
\phi(p, T x) \leq \phi(p, x), \quad \forall x \in C, \forall p \in F(T) .
$$

Recall that $T$ is said to be asymptotically quasi- $\phi$-nonexpansive iff there exists a sequence $\left\{\mu_{n}\right\} \subset[0, \infty)$ with $\mu_{n} \rightarrow 0$ as $n \rightarrow \infty$ such that

$$
F(T) \neq \emptyset, \quad \phi\left(p, T^{n} x\right) \leq\left(1+\mu_{n}\right) \phi(p, x), \quad \forall x \in C, \forall p \in F(T), \forall n \geq 1 .
$$

Remark 2.2 The class of asymptotically quasi- $\phi$-nonexpansive mappings [14, 29] which is an extension of the class of quasi- $\phi$-nonexpansive mappings [8]. The class of quasi$\phi$-nonexpansive mappings and the class of asymptotically quasi- $\phi$-nonexpansive mappings are more general than the class of relatively nonexpansive mappings and the class of relatively asymptotically nonexpansive mappings. Quasi- $\phi$-nonexpansive mappings and asymptotically quasi- $\phi$-nonexpansive ones do not require the restriction $F(T)=\widetilde{F}(T)$.

In order to prove our main results, we need the following lemmas.

Lemma 2.3 [30] Let E be a smooth and uniformly convex Banach space and let $r>0$. Then there exists a strictly increasing, continuous, and convex function $g:[0,2 r] \rightarrow R$ such that $g(0)=0$ and

$$
\left\|\sum_{i=1}^{\infty}\left(\alpha_{i} x_{i}\right)\right\|^{2} \leq \sum_{i=1}^{\infty}\left(\alpha_{i}\left\|x_{i}\right\|^{2}\right)-\alpha_{i} \alpha_{j} g\left(\left\|x_{i}-x_{j}\right\|\right),
$$

for all $x_{1}, x_{2}, \ldots, x_{N}, \ldots \in B_{r}:=\{x \in E:\|x\| \leq r\}$ and $\alpha_{1}, \alpha_{2}, \ldots, \alpha_{N}, \ldots \in[0,1]$ such that $\sum_{i=1}^{\infty} \alpha_{i}=1$. 
Lemma 2.4 [27] Let E be a reflexive, strictly convex, and smooth Banach space. Let $C$ be a nonempty, closed, and convex subset of $E$ and let $x \in E$. Then

$$
\phi\left(y, \Pi_{C} x\right)+\phi\left(\Pi_{C} x, x\right) \leq \phi(y, x), \quad \forall y \in C .
$$

Lemma 2.5 [27] Let C be a nonempty, closed, and convex subset of a smooth Banach space $E$ and let $x \in E$. Then $x_{0}=\Pi_{C} x$ if and only if

$$
\left\langle x_{0}-y, J x-J x_{0}\right\rangle \geq 0 \quad \forall y \in C .
$$

Lemma 2.6 [31] Let E be a uniformly smooth and strictly convex Banach space which also enjoys the Kadec-Klee property and let $C$ be a nonempty, closed, and convex subset of $E$. Let $T: C \rightarrow C$ be an asymptotically quasi- $\phi$-nonexpansive mapping. Then $F(T)$ is closed and convex.

Lemma $2.7[8,32]$ Let $C$ be a closed and convex subset of a smooth, strictly convex, and reflexive Banach space $E$. Let $F$ be a bifunction from $C \times C$ to $\mathbb{R}$ satisfying the assumptions (A1)-(A4). Let $r>0$ and let $x \in E$. Then there exists $z \in C$ such that $F(z, y)+\frac{1}{r}\langle y-z, J z-J x\rangle \geq 0, \forall y \in C$. Define a mapping $T_{r}: E \rightarrow C$ by

$$
S_{r} x=\left\{z \in C: f(z, y)+\frac{1}{r}\langle y-z, J z-J x\rangle, \forall y \in C\right\} .
$$

Then the following conclusions hold:

(1) $S_{r}$ is a single-valued firmly nonexpansive-type mapping, i.e., for all $x, y \in E$,

$$
\left\langle S_{r} x-S_{r} y, J S_{r} x-J S_{r} y\right\rangle \leq\left\langle S_{r} x-S_{r} y, J x-J y\right\rangle
$$

(2) $F\left(S_{r}\right)=E P(F)$ is closed and convex;

(3) $S_{r}$ is quasi- $\phi$-nonexpansive;

(4) $\phi\left(q, S_{r} x\right)+\phi\left(S_{r} x, x\right) \leq \phi(q, x), \forall q \in F\left(S_{r}\right)$.

\section{Main results}

Theorem 3.1 Let E be a uniformly smooth and strictly convex Banach space which also has the Kadec-Klee property. Let $C$ be a nonempty, closed, and convex subset of $E$ and let $\Delta$ be an index set. Let $F_{j}$ be a bifunction from $C \times C$ to $\mathbb{R}$ satisfying (A1)-(A4) for every $j \in \Delta$. Let $T_{i}: C \rightarrow C$ an asymptotically quasi- $\phi$-nonexpansive mapping for every $i \geq 1$. Assume that $T_{i}$ is closed asymptotically regular on $C$ and $\bigcap_{i=1}^{\infty} F\left(T_{i}\right) \cap \bigcap_{j \in \Delta} E P\left(F_{j}\right)$ is nonempty and bounded. Let $\left\{x_{n}\right\}$ be a sequence generated in the following manner:

$$
\left\{\begin{array}{l}
x_{0} \in E, \quad \text { chosen arbitrarily, } \\
C_{1, j}=C, \\
C_{1}=\bigcap_{j \in \Delta} C_{1, j}, \\
x_{1}=\prod_{C_{1}} x_{0}, \\
y_{n}=J^{-1}\left(\alpha_{n, 0} J x_{n}+\sum_{i=1}^{\infty} \alpha_{n, j} J T_{i}^{n} x_{n}\right), \\
u_{n, j} \in C \text { such that } F_{j}\left(u_{n, j}, y\right)+\frac{1}{r_{n, j}}\left\langle y-u_{n, j}, J u_{n, j}-J y_{n}\right\rangle \geq 0, \quad \forall y \in C, \\
C_{n+1, j}=\left\{z \in C_{n}: \phi\left(z, u_{n, j}\right) \leq \phi\left(z, x_{n}\right)+\sum_{i=1}^{\infty} \mu_{n, i} M_{n}\right\}, \\
C_{n+1}=\bigcap_{j \in \Delta} C_{n+1, j}, \\
x_{n+1}=\prod_{C_{n+1}} x_{0},
\end{array}\right.
$$


where $\left\{\alpha_{n, i}\right\}$ is a real number sequence in $(0,1)$ for every $i \geq 1,\left\{r_{n, j}\right\}$ is a real number sequence in $[r, \infty)$, where $r$ is some positive real number and $M_{n}:=\sup \left\{\phi\left(z, x_{n}\right): z \in \bigcap_{i=1}^{\infty} F\left(T_{i}\right) \cap\right.$ $\left.\bigcap_{j \in \Delta} E P\left(F_{j}\right)\right\}$. Assume that $\sum_{i=0}^{\infty} \alpha_{n, i}=1$ and $\liminf _{n \rightarrow \infty} \alpha_{n, 0} \alpha_{n, i}>0$ for every $i \geq 1$. Then the sequence $\left\{x_{n}\right\}$ converges strongly to $\Pi_{\bigcap_{i=1}^{\infty} F\left(T_{i}\right) \cap \bigcap_{j \in \Delta} E P\left(F_{j}\right)} x_{0}$, where $\Pi_{\bigcap_{i=1}^{\infty} F\left(T_{i}\right) \cap \bigcap_{j \in \Delta} E P\left(F_{j}\right)}$ is the generalized projection from $E$ onto $\bigcap_{i=1}^{\infty} F\left(T_{i}\right) \cap \bigcap_{j \in \Delta} E P\left(F_{j}\right)$.

Proof Using Lemma 2.6 and Lemma 2.7, we find that $\bigcap_{i=1}^{\infty} F\left(T_{i}\right) \cap \bigcap_{j \in \Delta} E P\left(F_{j}\right)$ is closed and convex so that $\prod_{\bigcap_{i=1}^{\infty} F\left(T_{i}\right) \cap \bigcap_{j \in \Delta} E P\left(F_{j}\right)} x_{0}$ is well defined. By induction, we easily find that the sets $C_{n}$ are convex and closed.

Next, we show that $\bigcap_{i=1}^{\infty} F\left(T_{i}\right) \cap \bigcap_{j \in \Delta} E F\left(F_{j}\right) \subset C_{n}$. It suffices to claim that

$$
\bigcap_{i=1}^{\infty} F\left(T_{i}\right) \cap \bigcap_{j \in \Delta} E F\left(F_{j}\right) \subset C_{n, j}
$$

for every $j \in \Delta$. It is clear that $\bigcap_{i=1}^{\infty} F\left(T_{i}\right) \cap \bigcap_{j \in \Delta} E F\left(F_{j}\right) \subset C_{1, j}=C$. Now, we assume that $\bigcap_{i=1}^{\infty} F\left(T_{i}\right) \cap \bigcap_{j \in \Delta} E F\left(F_{j}\right) \subset C_{m, j}$ for some $m$ and for every $j \in \Delta$. Since $\forall z \in \bigcap_{i=1}^{\infty} F\left(T_{i}\right) \cap$ $\bigcap_{j \in \Delta} E F\left(F_{j}\right) \subset C_{m, j}$, one finds that

$$
\begin{aligned}
\phi\left(z, u_{m, j}\right)= & \phi\left(z, S_{r_{m, j}} y_{m}\right) \\
\leq & \phi\left(z, y_{m}\right) \\
= & \phi\left(z, J^{-1}\left(\alpha_{m, 0} J x_{m}+\sum_{i=1}^{\infty} \alpha_{m, j} T_{i}^{m} x_{m}\right)\right) \\
= & \|z\|^{2}-2\left\langle z, \alpha_{m, 0} J x_{m}+\sum_{i=1}^{\infty} \alpha_{m, i} J T_{i}^{m} x_{m}\right\rangle+\left\|\alpha_{m, 0} J x_{m}+\sum_{i=1}^{\infty} \alpha_{m, i} J T_{i}^{m} x_{m}\right\|^{2} \\
\leq & \|z\|^{2}-2 \alpha_{m, 0}\left\langle z, J x_{m}\right\rangle-2 \sum_{i=1}^{\infty} \alpha_{m, i}\left|z, J T_{i}^{m} x_{m}\right\rangle \\
& +\alpha_{m, 0}\left\|x_{m}\right\|^{2}+\sum_{i=1}^{\infty} \alpha_{m, i}\left\|T_{i}^{m} x_{m}\right\|^{2} \\
= & \alpha_{m, 0} \phi\left(z, x_{m}\right)+\sum_{i=1}^{\infty} \alpha_{m, i} \phi\left(z, T_{i}^{m} x_{m}\right) \\
\leq & \alpha_{m, 0} \phi\left(z, x_{m}\right)+\sum_{i=1}^{\infty} \alpha_{m, i} \phi\left(z, x_{m}\right)+\sum_{i=1}^{\infty} \alpha_{m, i} \mu_{m, i} \phi\left(z, x_{m}\right) \\
\leq & \phi\left(z, x_{m}\right)+\sum_{i=1}^{\infty} \mu_{m, i} \phi\left(z, x_{m}\right) \\
\leq & \phi\left(z, x_{m}\right)+\sum_{i=1}^{\infty} \mu_{m, i} M_{m},
\end{aligned}
$$

which yields $z \in C_{m+1, j}$, that is, $\bigcap_{i=1}^{\infty} F\left(T_{i}\right) \cap \bigcap_{j \in \Delta} E F\left(F_{j}\right) \subset C_{n}$.

Next, we prove that $x_{n} \rightarrow p$, where $p \in \bigcap_{i=1}^{\infty} F\left(T_{i}\right) \cap \bigcap_{j \in \Delta} E F\left(F_{j}\right)$. It follows from Lemma 2.4 that $\phi\left(x_{n}, x_{0}\right) \leq \phi\left(w, x_{0}\right)-\phi\left(w, x_{n}\right) \leq \phi\left(w, x_{0}\right)$, for $\forall w \in \bigcap_{i=1}^{N} F\left(T_{i}\right) \cap$ $\bigcap_{j \in \Delta} E F\left(F_{j}\right)$. This shows that the sequence $\phi\left(x_{n}, x_{0}\right)$ is bounded. Hence $\left\{x_{n}\right\}$ is also 
bounded. Since the space is reflexive, we may, without loss of generality, assume that $x_{n} \rightarrow p$, where $p \in C_{n}$. Using $\phi\left(x_{n}, x_{0}\right) \leq \phi\left(p, x_{0}\right)$, we find that

$$
\phi\left(p, x_{0}\right) \leq \liminf _{n \rightarrow \infty} \phi\left(x_{n}, x_{0}\right) \leq \limsup _{n \rightarrow \infty} \phi\left(x_{n}, x_{0}\right) \leq \phi\left(p, x_{0}\right) .
$$

It follows that $\lim _{n \rightarrow \infty} \phi\left(x_{n}, x_{0}\right)=\phi\left(p, x_{0}\right)$. Hence, we have $\lim _{n \rightarrow \infty}\left\|x_{n}\right\|=\|p\|$. Since $E$ has the Kadec-Klee property, one sees that $x_{n} \rightarrow p$ as $n \rightarrow \infty$. Next, we prove $p \in \bigcap_{j \in \Delta} E F\left(F_{j}\right)$. In view of $C_{n+1} \subset C_{n}$ and $x_{n+1}=\Pi_{C_{n+1} x_{0}} \in C_{n}$, we have $\phi\left(x_{n+1}, x_{n}\right) \leq$ $\phi\left(x_{n+1}, x_{0}\right)-\phi\left(x_{n}, x_{0}\right)$. Letting $n \rightarrow \infty$, we obtain $\phi\left(x_{n+1}, x_{n}\right) \rightarrow 0$. Since $x_{n+1} \in C_{n+1}$, we see that $\phi\left(x_{n+1}, u_{n, j}\right) \leq \phi\left(x_{n+1}, x_{n}\right)+\sum_{i=1}^{\infty} \mu_{n, i} M_{n}$. We, therefore, obtain $\lim _{n \rightarrow \infty} \phi\left(x_{n+1}, u_{n, j}\right)=0$. Hence $\lim _{n \rightarrow \infty}\left\|u_{n, j}\right\|=\|p\|$. It follows that $\lim _{n \rightarrow \infty}\left\|J u_{n, j}\right\|=\|J p\|$. This shows that $\left\{J u_{n, j}\right\}$ is a bounded sequence. Since $E$ is reflexive ( $E^{*}$ is also reflexive), we may assume that $J u_{n, j} \rightarrow$ $u^{*, j} \in E^{*}$. Using the reflexivity of $E$, we also see that $J(E)=E^{*}$. This shows that there exists an $u^{j} \in E$ such that $J u^{j}=u^{*, j}$. It follows that $\phi\left(x_{n+1}, u_{n}\right)=\left\|x_{n+1}\right\|^{2}-2\left\langle x_{n+1}, J u_{n}\right\rangle+\left\|J u_{n}\right\|^{2}$. Taking $\liminf _{n \rightarrow \infty}$ in both sides of the equality above yields

$$
\begin{aligned}
0 & \geq\|p\|^{2}-2\left\langle p, u^{*, j}\right\rangle+\left\|u^{*, j}\right\|^{2} \\
& =\|p\|^{2}-2\left\langle p, J u^{j}\right\rangle+\left\|J u^{j}\right\|^{2} \\
& =\phi\left(p, u^{j}\right),
\end{aligned}
$$

that is, $p=u^{j}$. This yields $J p=u^{*, j}$. It follows that $J u_{n, j} \rightarrow J p \in E^{*}$. Since $E^{*}$ has the KadecKlee property, we obtain $J u_{n, j}-J p \rightarrow 0$ as $n \rightarrow \infty$. Since $J^{-1}: E^{*} \rightarrow E$ is demicontinuous. It follows that $u_{n, j} \rightarrow p$. Since the space $E$ has the Kadec-Klee property, one finds that $u_{n, j} \rightarrow p$ as $n \rightarrow \infty$. In view of $\left\|x_{n}-u_{n, j}\right\| \leq\left\|x_{n}-p\right\|+\left\|p-u_{n, j}\right\|$, we have $\lim _{n \rightarrow \infty}\left\|x_{n}-u_{n, j}\right\|=0$. It follows that $\lim _{n \rightarrow \infty}\left\|J x_{n}-J u_{n, j}\right\|=0$. Notice that

$$
\begin{aligned}
\phi\left(z, x_{n}\right)-\phi\left(z, u_{n, j}\right) & =\left\|x_{n}\right\|^{2}-\left\|u_{n, j}\right\|^{2}-2\left\langle z, J x_{n}-J u_{n, j}\right\rangle \\
& \leq\left\|x_{n}-u_{n, j}\right\|\left(\left\|x_{n}\right\|+\left\|u_{n, j}\right\|\right)+2\|z\|\left\|J x_{n}-J u_{n, j}\right\| .
\end{aligned}
$$

It follows that $\lim _{n \rightarrow \infty} \phi\left(z, x_{n}\right)-\phi\left(z, u_{n, j}\right)=0$. By virtue of (3.1), we find that $\phi\left(z, y_{n}\right) \leq$ $\phi\left(z, x_{n}\right)+\sum_{i=1}^{N} \mu_{n, j} M_{n}$, where $z \in \bigcap_{i=1}^{\infty} F\left(T_{i}\right) \cap \bigcap_{j \in \Delta} E F\left(F_{j}\right)$. In view of $u_{n, j}=S_{r_{n, j}} y_{n}$, we find from Lemma 2.7 that

$$
\begin{aligned}
\phi\left(u_{n, j}, y_{n}\right) & =\phi\left(S_{r_{n, j}} y_{n}, y_{n}\right) \\
& \leq \phi\left(z, y_{n}\right)-\phi\left(z, S_{r_{n, j}} y_{n}\right) \\
& \leq \phi\left(z, x_{n}\right)-\phi\left(z, S_{r_{n, j}} y_{n}\right)+\sum_{i=1}^{\infty} \mu_{n, j} M_{n} \\
& =\phi\left(z, x_{n}\right)-\phi\left(z, u_{n, j}\right)+\sum_{i=1}^{\infty} \mu_{n, j} M_{n} .
\end{aligned}
$$

It follows that $\lim _{n \rightarrow \infty} \phi\left(u_{n, j}, y_{n}\right)=0$. This in turn yields that $\left\|u_{n, j}\right\|-\left\|y_{n}\right\| \rightarrow 0$ as $n \rightarrow \infty$. Since $u_{n, j} \rightarrow p$ as $n \rightarrow \infty$, one finds that $\lim _{n \rightarrow \infty}\left\|y_{n}\right\|=\|p\|$. It follows that $\lim _{n \rightarrow \infty}\left\|J y_{n}\right\|=\|J p\|$. Since $E^{*}$ is also reflexive, we may assume that $J y_{n} \rightarrow y^{*} \in E^{*}$. In view 
of $J(E)=E^{*}$, we see that there exists $y \in E$ such that $J y=y^{*}$. It follows that

$$
\phi\left(u_{n, j}, y_{n}\right)=\left\|u_{n, j}\right\|^{2}-2\left\langle u_{n, j}, J y_{n}\right\rangle+\left\|J y_{n}\right\|^{2} .
$$

Taking $\liminf \operatorname{in}_{n \rightarrow \infty}$ in both sides of the equality above yields

$$
\begin{aligned}
0 & \geq\|p\|^{2}-2\left\langle p, y^{*}\right\rangle+\left\|y^{*}\right\|^{2} \\
& =\|p\|^{2}-2\langle p, J y\rangle+\|J y\|^{2} \\
& =\phi(p, y) .
\end{aligned}
$$

That is, $p=y$, which in turn implies that $y^{*}=J p$. It follows that $J y_{n} \rightarrow J p \in E^{*}$. Since the space $E^{*}$ has the Kadec-Klee property, we arrive at $J y_{n}-J p \rightarrow 0$ as $n \rightarrow \infty$. Note that $J^{-1}: E^{*} \rightarrow E$ is demicontinuous. It follows that $y_{n} \rightarrow p$. Since $E$ has the Kadec-Klee property, we obtain $y_{n} \rightarrow p$ as $n \rightarrow \infty$. In view of $\left\|u_{n, j}-y_{n}\right\| \leq\left\|u_{n, j}-p\right\|+\left\|p-y_{n}\right\|$, we find that $\lim _{n \rightarrow \infty}\left\|u_{n, i}-y_{n}\right\|=0$. Since $J$ is uniformly norm-to-norm continuous on any bounded sets, we have $\lim _{n \rightarrow \infty}\left\|J u_{n, j}-J y_{n}\right\|=0$. From the assumption $r_{n, j} \geq r_{j}$, we see that $\lim _{n \rightarrow \infty} \frac{\left\|u_{n, j}-J y_{n}\right\|}{r_{n, j}}=0$. Notice that

$$
F_{j}\left(u_{n, j}, y\right)+\frac{1}{r_{n, j}}\left\langle y-u_{n, j}, J u_{n, j}-J y_{n}\right\rangle \geq 0, \quad \forall y \in C .
$$

From the condition (A2), we find that

$$
\left\|y-u_{n, j}\right\| \frac{\left\|J u_{n, j}-J y_{n}\right\|}{r_{n, j}} \geq \frac{1}{r_{n, j}}\left\langle y-u_{n, j}, J u_{n, j}-J y_{n}\right\rangle \geq F_{j}\left(y, u_{n, j}\right), \quad \forall y \in C .
$$

Taking the limit as $n \rightarrow \infty$, we find that $F_{j}(y, p) \leq 0, \forall y \in C$. For $0<t_{j}<1$ and $y \in C$, define $y_{t_{j}}=t_{j} y+\left(1-t_{j}\right) p$. It follows that $y_{t, j} \in C$, which yields $F_{j}\left(y_{t, j}, p\right) \leq 0$. It follows from the conditions (A1) and (A4) that

$$
0=F_{j}\left(y_{t, j}, y_{t, j}\right) \leq t_{j} F_{j}\left(y_{t, j}, y\right)+\left(1-t_{j}\right) F_{j}\left(y_{t, j}, p\right) \leq t_{j} F_{j}\left(y_{t, j}, y\right)
$$

This yields $F_{j}\left(y_{t, j}, y\right) \geq 0$. Letting $t_{j} \rightarrow 0$, we find from the condition (A3) that $F_{j}(p, y) \geq 0$, $\forall y \in C$. This implies that $p \in E P\left(F_{j}\right)$ for every $j \in \Delta$.

Now, we are in a position to show that $p \in \bigcap_{i=1}^{\infty} F\left(T_{i}\right)$. It follows from Lemma 2.3 that

$$
\begin{aligned}
\phi\left(z, u_{n, j}\right) \leq & \phi\left(z, y_{n}\right) \\
= & \phi\left(z, J^{-1}\left(\alpha_{n, 0} J x_{n}+\sum_{i=1}^{\infty} \alpha_{n, i} J T_{i}^{n} x_{n}\right)\right) \\
= & \|z\|^{2}-2\left\langle z, \alpha_{n, 0} J x_{n}+\sum_{i=1}^{\infty} \alpha_{n, i} J T_{i}^{n} x_{n}\right\rangle+\left\|\alpha_{n, 0} J x_{n}+\sum_{i=1}^{\infty} \alpha_{n, i} J T_{i}^{n} x_{n}\right\|^{2} \\
\leq & \|z\|^{2}-2 \alpha_{n, 0}\left\langle z, J x_{n}\right\rangle-2 \sum_{i=1}^{\infty} \alpha_{n, i}\left\langle z, J T_{i}^{n} x_{n}\right\rangle \\
& +\alpha_{n, 0}\left\|x_{n}\right\|^{2}+\sum_{i=1}^{\infty} \alpha_{n, i}\left\|T_{i}^{n} x_{n}\right\|^{2}-\alpha_{n, 0}\left(1-\alpha_{n, i}\right) g\left(\left\|J x_{n}-J T_{i}^{n} x_{n}\right\|\right)
\end{aligned}
$$




$$
\begin{aligned}
= & \alpha_{n, 0} \phi\left(z, x_{m}\right)+\sum_{i=1}^{\infty} \alpha_{n, i} \phi\left(z, T_{i}^{n} x_{n}\right)-\alpha_{n, 0}\left(1-\alpha_{n, i}\right) g\left(\left\|J x_{n}-J T_{i}^{n} x_{n}\right\|\right) \\
\leq & \alpha_{n, 0} \phi\left(z, x_{m}\right)+\sum_{i=1}^{\infty} \alpha_{n, i} \phi\left(z, x_{m}\right)+\sum_{i=1}^{\infty} \alpha_{n, i} \mu_{n, i} \phi\left(z, x_{n}\right) \\
& -\alpha_{n, 0}\left(1-\alpha_{n, i}\right) g\left(\left\|J x_{n}-J T_{i}^{n} x_{n}\right\|\right) \\
\leq & \phi\left(z, x_{n}\right)+\sum_{i=1}^{\infty} \mu_{n, i} \phi\left(z, x_{m}\right)-\alpha_{n, 0}\left(1-\alpha_{n, i}\right) g\left(\left\|J x_{n}-J T_{i}^{n} x_{n}\right\|\right) \\
\leq & \phi\left(z, x_{n}\right)+\sum_{i=1}^{\infty} \mu_{n, i} M_{n}-\alpha_{n, 0}\left(1-\alpha_{n, i}\right) g\left(\left\|J x_{n}-J T_{i}^{n} x_{n}\right\|\right) .
\end{aligned}
$$

From $\liminf _{n \rightarrow \infty} \alpha_{n, 0}\left(1-\alpha_{n, i}\right)>0$, we find that $\lim _{n \rightarrow \infty} g\left(\left\|J x_{n}-J T_{i}^{n} x_{n}\right\|\right)=0$. Hence, we have

$$
\lim _{n \rightarrow \infty}\left\|J x_{n}-J T_{i}^{n} x_{n}\right\|=0
$$

Since $x_{n} \rightarrow p$ as $n \rightarrow \infty$ and $J: E \rightarrow E^{*}$ is demicontinuous, we obtain $J x_{n} \rightarrow J p \in E^{*}$. Note that $\left|\left\|J x_{n}\right\|-\|J p\|\right|=\left|\left\|x_{n}\right\|-\|p\|\right| \leq\left\|x_{n}-p\right\|$. This implies that $\left\|J x_{n}\right\| \rightarrow\|J p\|$ as $n \rightarrow \infty$. Since $E^{*}$ has the Kadec-Klee property, we see that

$$
\lim _{n \rightarrow \infty}\left\|J x_{n}-J p\right\|=0
$$

On the other hand, we have $\left\|J T_{i}^{n} x_{n}-J p\right\| \leq\left\|J T_{i}^{n} x_{n}-J x_{n}\right\|+\left\|J x_{n}-J p\right\|$. Combining (3.2) with (3.3), one obtains that $\lim _{n \rightarrow \infty}\left\|J T_{i}^{n} x_{n}-J p\right\|=0$. Since $J^{-1}: E^{*} \rightarrow E$ is demicontinuous, one sees that $T_{i}^{n} x_{n} \rightarrow p$. Notice that

$$
\left|\left\|T_{i}^{n} x_{n}\right\|-\|p\|\right|=\left|\left\|J T_{i}^{n} x_{n}\right\|-\|J p\|\right| \leq\left\|J T_{i}^{n} x_{n}-J p\right\| .
$$

This yields $\lim _{n \rightarrow \infty}\left\|T_{i}^{n} x_{n}\right\|=\|p\|$. Since the space $E$ has the Kadec-Klee property, we obtain $\lim _{n \rightarrow \infty}\left\|T_{i}^{n} x_{n}-p\right\|=0$. Since $\left\|T^{n+1} x_{n}-p\right\| \leq\left\|T^{n+1} x_{n}-T^{n} x_{n}\right\|+\left\|T^{n} x_{n}-p\right\|$ and $T$ is asymptotically regular, we find that $\lim _{n \rightarrow \infty}\left\|T_{i}^{n+1} x_{n}-p\right\|=0$. That is, $T_{i} T_{i}^{n} x_{n}-p \rightarrow 0$ as $n \rightarrow \infty$. It follows from the closedness of $T_{i}$ that $T_{i} p=p$ for every $i \geq 1$.

Finally, we prove that $p=\Pi_{\bigcap_{i=1}^{\infty} F\left(T_{i}\right) \cap \bigcap_{j \in \Delta} E F\left(F_{j}\right)} x_{0}$. Since $x_{n}=\Pi_{C_{n}} x_{0}$, we see that

$$
\left\langle x_{n}-z, J x_{0}-J x_{n}\right\rangle \geq 0, \quad \forall z \in C_{n} .
$$

Since $\bigcap_{i=1}^{\infty} F\left(T_{i}\right) \cap \bigcap_{j \in \Delta} E P\left(F_{j}\right) \subset C_{n}$, we find that

$$
\left\langle x_{n}-w, J x_{0}-J x_{n}\right\rangle \geq 0, \quad \forall w \in \bigcap_{i=1}^{N} F\left(T_{i}\right) \cap \bigcap_{j \in \Delta} E F\left(F_{j}\right) .
$$

Letting $n \rightarrow \infty$, we arrive at $\left\langle p-w, J x_{0}-J p\right\rangle \geq 0, \forall w \in \bigcap_{i=1}^{\infty} F\left(T_{i}\right) \cap \bigcap_{j \in \Delta} E P\left(F_{j}\right)$. In view of Lemma 2.5, we find that $p=\prod_{\bigcap_{i=1}^{\infty} F\left(T_{i}\right) \cap \bigcap_{j \in \Delta} E F\left(F_{j}\right)} x_{0}$. This completes the proof.

Remark 3.2 Theorem 3.1 mainly improves the corresponding results in Kim [11] and Qin et al. [33].

If $T$ is quasi- $\phi$-nonexpansive, we have the following result. 
Corollary 3.3 Let E be a uniformly smooth and strictly convex Banach space which also has the Kadec-Klee property. Let $C$ be a nonempty, closed, and convex subset of $E$ and let $\Delta$ be an index set. Let $F_{j}$ be a bifunction from $C \times C$ to $\mathbb{R}$ satisfying (A1)-(A4) for every $j \in \Delta$. Let $T_{i}: C \rightarrow C$ a quasi- $\phi$-nonexpansive mapping for every $i \geq 1$. Assume that $T_{i}$ is closed on $C$ and $\bigcap_{i=1}^{\infty} F\left(T_{i}\right) \cap \bigcap_{j \in \Delta} E P\left(F_{j}\right)$ is nonempty. Let $\left\{x_{n}\right\}$ be a sequence generated in the following manner:

$$
\left\{\begin{array}{l}
x_{0} \in E, \quad \text { chosen arbitrarily, } \\
C_{1, j}=C, \\
C_{1}=\bigcap_{j \in \Delta} C_{1, j}, \\
x_{1}=\prod_{C_{1}} x_{0}, \\
y_{n}=J^{-1}\left(\alpha_{n, 0} J x_{n}+\sum_{i=1}^{\infty} \alpha_{n, j} J T_{i} x_{n}\right), \\
u_{n, j} \in C \text { such that } F_{j}\left(u_{n, j}, y\right)+\frac{1}{r_{n, j}}\left\langle y-u_{n, j}, J u_{n, j}-J y_{n}\right\rangle \geq 0, \quad \forall y \in C, \\
C_{n+1, j}=\left\{z \in C_{n}: \phi\left(z, u_{n, j}\right) \leq \phi\left(z, x_{n}\right)\right\}, \\
C_{n+1}=\bigcap_{j \in \Delta} C_{n+1, j}, \\
x_{n+1}=\prod_{C_{n+1}} x_{0},
\end{array}\right.
$$

where $\left\{\alpha_{n, i}\right\}$ is a real number sequence in $(0,1)$ for every $i \geq 1,\left\{r_{n, j}\right\}$ is a real number sequence in $[r, \infty)$, where $r$ is some positive real number. Assume that $\sum_{i=0}^{N} \alpha_{n, i}=1$ and $\liminf _{n \rightarrow \infty} \alpha_{n, 0} \alpha_{n, i}>0$ for every $i \geq 1$. Then the sequence $\left\{x_{n}\right\}$ converges strongly to $\Pi_{\bigcap_{i=1}^{\infty} F\left(T_{i}\right) \cap \bigcap_{j \in \Delta} E P\left(F_{j}\right)} x_{0}$, where $\prod_{\bigcap_{i=1}^{\infty} F\left(T_{i}\right) \cap \bigcap_{j \in \Delta} E P\left(F_{j}\right)}$ is the generalized projection from $E$ onto $\bigcap_{i=1}^{\infty} F\left(T_{i}\right) \cap \bigcap_{j \in \Delta} E P\left(F_{j}\right)$.

Remark 3.4 Corollary 3.3 mainly improves the corresponding results in Qin et al. [8]. Indeed, the space is extended from a uniformly smooth and uniformly convex Banach space to a uniformly smooth and strictly convex Banach space; the mapping is extended from a pari of mappings to infinite many mappings. We also remark here that the framework of the space in this paper can be applicable to $L^{p}, p \geq 1$.

Finally for a single mapping and bifunction, we have the following result.

Corollary 3.5 Let E be a uniformly smooth and strictly convex Banach space which also has the Kadec-Klee property. Let $C$ be a nonempty, closed, and convex subset of $E$ and let $F$ be a bifunction from $C \times C$ to $\mathbb{R}$ satisfying (A1)-(A4). Let $T: C \rightarrow C$ an asymptotically quasi- $\phi$-nonexpansive mapping. Assume that $T$ is closed asymptotically regular on $C$ and $F(T) \cap E P(F)$ is nonempty and bounded. Let $\left\{x_{n}\right\}$ be a sequence generated in the following manner:

$$
\left\{\begin{array}{l}
x_{0} \in E, \quad \text { chosen arbitrarily, } \\
C_{1}=C, \\
x_{1}=\Pi_{C_{1} x_{0}}, \\
y_{n}=J^{-1}\left(\alpha_{n} J x_{n}+\left(1-\alpha_{n}\right) J T^{n} x_{n}\right), \\
u_{n} \in C \text { such that } F\left(u_{n}, y\right)+\frac{1}{r_{n}}\left\langle y-u_{n}, J u_{n}-J y_{n}\right\rangle \geq 0, \quad \forall y \in C, \\
C_{n+1}=\left\{z \in C_{n}: \phi\left(z, u_{n}\right) \leq \phi\left(z, x_{n}\right)+\mu_{n} M_{n}\right\}, \\
x_{n+1}=\Pi_{C_{n+1}} x_{0},
\end{array}\right.
$$


where $\left\{\alpha_{n}\right\}$ is a real number sequence in $(0,1),\left\{r_{n}\right\}$ is a real number sequence in $[r, \infty)$, where $r$ is some positive real number and $M_{n}:=\sup \left\{\phi\left(z, x_{n}\right): z \in F(T) \cap E P(F)\right\}$. Assume $\liminf _{n \rightarrow \infty} \alpha_{n}\left(1-\alpha_{n}\right)>0$. Then the sequence $\left\{x_{n}\right\}$ converges strongly to $\Pi_{F(T) \cap E P(F)} x_{0}$, where $\Pi_{F(T) \cap E P(F)}$ is the generalized projection from $E$ onto $F(T) \cap E P(F)$.

\section{Applications}

First, we give the corresponding results in the framework of Hilbert spaces.

Theorem 4.1 Let E be a Hilbert space. Let $C$ be a nonempty, closed, and convex subset of $E$ and let $\Delta$ be an index set. Let $F_{j}$ be a bifunction from $C \times C$ to $\mathbb{R}$ satisfying (A1)-(A4) for every $j \in \Delta$. Let $T_{i}: C \rightarrow C$ an asymptotically quasi-nonexpansive mapping for every $i \geq 1$. Assume that $T_{i}$ is closed asymptotically regular on $C$ and $\bigcap_{i=1}^{\infty} F\left(T_{i}\right) \cap \bigcap_{j \in \Delta} E P\left(F_{j}\right)$ is nonempty and bounded. Let $\left\{x_{n}\right\}$ be a sequence generated in the following manner:

$$
\left\{\begin{array}{l}
x_{0} \in E, \quad \text { chosen arbitrarily, } \\
C_{1, j}=C, \\
C_{1}=\bigcap_{j \in \Delta} C_{1, j}, \\
x_{1}=\operatorname{Proj}_{C_{1}} x_{0}, \\
y_{n}=\alpha_{n, 0} x_{n}+\sum_{i=1}^{\infty} \alpha_{n, i} T_{i}^{n} x_{n}, \\
u_{n, j} \in C \text { such that } F_{j}\left(u_{n, j}, y\right)+\frac{1}{r_{n, j}}\left\langle y-u_{n, j}, u_{n, j}-y_{n}\right\rangle \geq 0, \quad \forall y \in C, \\
C_{n+1, j}=\left\{z \in C_{n}:\left\|z-u_{n, j}\right\|^{2} \leq\left\|z-x_{n}\right\|^{2}+\sum_{i=1}^{\infty} \mu_{n, i} M_{n}\right\}, \\
C_{n+1}=\bigcap_{j \in \Delta} C_{n+1, j}, \\
x_{n+1}=\operatorname{Proj}_{C_{n+1}} x_{0},
\end{array}\right.
$$

where $\left\{\alpha_{n, i}\right\}$ is a real number sequence in $(0,1)$ for every $i \geq 1,\left\{r_{n, j}\right\}$ is a real number sequence in $[r, \infty)$, where $r$ is some positive real number and $M_{n}:=\sup \left\{\left\|z-x_{n}\right\|^{2}: z \in \bigcap_{i=1}^{\infty} F\left(T_{i}\right) \cap\right.$ $\left.\bigcap_{j \in \Delta} E P\left(F_{j}\right)\right\}$. Assume that $\sum_{i=0}^{\infty} \alpha_{n, i}=1$ and $\liminf _{n \rightarrow \infty} \alpha_{n, 0} \alpha_{n, i}>0$ for every $i \geq 1$. Then the sequence $\left\{x_{n}\right\}$ converges strongly to $\operatorname{Proj}_{\bigcap_{i=1}^{\infty} F\left(T_{i}\right) \cap \bigcap_{j \in \Delta} E P\left(F_{j}\right)} x_{0}$, where $\operatorname{Proj}_{\bigcap_{i=1}^{\infty} F\left(T_{i}\right) \cap \bigcap_{j \in \Delta} E P\left(F_{j}\right)}$ is the metric projection from $E$ onto $\bigcap_{i=1}^{\infty} F\left(T_{i}\right) \cap \bigcap_{j \in \Delta} E P\left(F_{j}\right)$.

Proof Note that $\phi(x, y)=\|x-y\|^{2}, J=I$, the identity mapping, and the generalized projection is reduced to the metric projection. In the framework of Hilbert spaces, the class of asymptotically quasi- $\phi$-nonexpansive mappings is reduced to the class of asymptotically quasi-nonexpansive mappings. Using Theorem 3.1, we easily find the desired conclusion.

Next, we give a results on common solutions of a family of equilibrium problems.

Corollary 4.2 Let E be a Hilbert space. Let $C$ be a nonempty, closed, and convex subset of $E$ and let $\Delta$ be an index set. Let $F_{j}$ be a bifunction from $C \times C$ to $\mathbb{R}$ satisfying (A1)-(A4) for every $j \in \Delta$. Assume that $\bigcap_{j \in \Delta} E P\left(F_{j}\right)$ is nonempty. Let $\left\{x_{n}\right\}$ be a sequence generated in the 
following manner:

$$
\left\{\begin{array}{l}
x_{0} \in E, \quad \text { chosen arbitrarily, } \\
C_{1, j}=C, \\
C_{1}=\bigcap_{j \in \Delta} C_{1, j}, \\
x_{1}=\operatorname{Proj}_{C_{1}} x_{0}, \\
u_{n, j} \in C \text { such that } F_{j}\left(u_{n, j}, y\right)+\frac{1}{r_{n, j}}\left\langle y-u_{n, j}, u_{n, j}-x_{n}\right\rangle \geq 0, \quad \forall y \in C, \\
C_{n+1, j}=\left\{z \in C_{n}:\left\|z-u_{n, j}\right\| \leq\left\|z-x_{n}\right\|\right\}, \\
C_{n+1}=\bigcap_{j \in \Delta} C_{n+1, j}, \\
x_{n+1}=\operatorname{Proj}_{C_{n+1}} x_{0},
\end{array}\right.
$$

where $\left\{r_{n, j}\right\}$ is a real number sequence in $[r, \infty)$, where $r$ is some positive real number. Then the sequence $\left\{x_{n}\right\}$ converges strongly to $\operatorname{Proj}_{\bigcap_{j \in \Delta} E P\left(F_{j}\right)} x_{0}$, where $\operatorname{Proj}_{\bigcap_{j \in \Delta} E P\left(F_{j}\right)}$ is the metric projection from $E$ onto $\bigcap_{j \in \Delta} E P\left(F_{j}\right)$.

If $F_{j}(x, y)=0$, then we find from Theorem 4.1 the following result.

Corollary 4.3 Let E be a Hilbert space and let $C$ be a nonempty, closed, and convex subset of E. Let $T_{i}: C \rightarrow C$ an asymptotically quasi-nonexpansive mapping for every $i \geq 1$. Assume that $T_{i}$ is closed asymptotically regular on $C$ and $\bigcap_{i=1}^{\infty} F\left(T_{i}\right)$ is nonempty and bounded. Let $\left\{x_{n}\right\}$ be a sequence generated in the following manner:

$$
\left\{\begin{array}{l}
x_{0} \in E, \quad \text { chosen arbitrarily, } \\
C_{1}=C, \\
x_{1}=\operatorname{Proj}_{C_{1}} x_{0}, \\
y_{n}=\alpha_{n, 0} x_{n}+\sum_{i=1}^{\infty} \alpha_{n, i} T_{i}^{n} x_{n}, \\
C_{n+1}=\left\{z \in C_{n}:\left\|z-y_{n}\right\|^{2} \leq\left\|z-x_{n}\right\|^{2}+\sum_{i=1}^{\infty} \mu_{n, i} M_{n}\right\}, \\
x_{n+1}=\operatorname{Proj}_{C_{n+1}} x_{0},
\end{array}\right.
$$

where $\left\{\alpha_{n, i}\right\}$ is a real number sequence in $(0,1)$ for every $i \geq 1$, and $M_{n}:=\sup \left\{\left\|z-x_{n}\right\|^{2}: z \in\right.$ $\left.\bigcap_{i=1}^{\infty} F\left(T_{i}\right)\right\}$. Assume that $\sum_{i=0}^{\infty} \alpha_{n, i}=1$ and $\liminf _{n \rightarrow \infty} \alpha_{n, 0} \alpha_{n, i}>0$ for every $i \geq 1$. Then the sequence $\left\{x_{n}\right\}$ converges strongly to $\operatorname{Proj}_{\bigcap_{i=1}^{\infty} F\left(T_{i}\right)} x_{0}$, where $\operatorname{Proj}_{\bigcap_{i=1}^{\infty} F\left(T_{i}\right)}$ is the metric projection from $E$ onto $\bigcap_{i=1}^{\infty} F\left(T_{i}\right)$.

Remark 4.4 Comparing with Theorem 2.2 in Kim and Xu [34], we have the following: (1) one mapping is extended to an infinite family of mappings; (2) the set $Q_{n}$ is relaxed; (3) the mapping is extended from asymptotically nonexpansive mappings to asymptotically quasi-nonexpansive mappings, which may not be continuous.

From Corollary 4.3, the following result is not hard to derive.

Corollary 4.5 Let E be a Hilbert space. Let $C$ be a nonempty, closed, and convex subset of $E$. Let $T: C \rightarrow C$ be a closed quasi-nonexpansive mapping. Let $\left\{x_{n}\right\}$ be a sequence gen- 
erated in the following manner:

$$
\left\{\begin{array}{l}
x_{0} \in E, \quad \text { chosen arbitrarily, } \\
C_{1}=C, \quad x_{1}=\operatorname{Proj}_{C_{1}} x_{0}, \\
y_{n}=\alpha_{n} x_{n}+\left(1-\alpha_{n}\right) T x_{n}, \\
C_{n+1}=\left\{z \in C_{n}:\left\|z-y_{n}\right\| \leq\left\|z-x_{n}\right\|\right\}, \\
x_{n+1}=\operatorname{Proj}_{C_{n+1}} x_{0},
\end{array}\right.
$$

where $\left\{\alpha_{n}\right\}$ is a real number sequence in $(0,1)$ such that $\liminf _{n \rightarrow \infty} \alpha_{n}\left(1-\alpha_{n}\right)>0$. Then the sequence $\left\{x_{n}\right\}$ converges strongly to $\operatorname{Proj}_{F(T)} x_{0}$, where $\operatorname{Proj}_{F(T)}$ is the metric projection from E onto $F(T)$.

Remark 4.6 Corollary 4.5 is a shrinking version of the corresponding results in Nakajo and Takahashi [35]. It deserves mentioning that the mapping in our result is quasinonexpansive. The restriction of the demiclosed principal is relaxed.

\section{Competing interests}

The authors declare that they have no competing interests.

\section{Authors' contributions}

Both authors contributed equally to this manuscript. Both authors read and approved the final manuscript.

\section{Author details}

${ }^{1}$ School of Mathematics and Information Science, North China University of Water Resources and Electric Power, Zhengzhou, 450011, China. ${ }^{2}$ College of Science, Hebei University of Engineering, Handan, 056038, China.

\section{Acknowledgements}

This paper is dedicated to Professor Chang with respect and admiration. The authors are grateful to the editor and the three anonymous reviewers for useful suggestions which improved the contents of the article.

Received: 13 March 2014 Accepted: 25 May 2014 Published: 03 Jun 2014

\section{References}

1. Vanderluge, A: Optical Signal Processing. Wiley, New York (2005)

2. Byrne, C: A unified treatment of some iterative algorithms in signal processing and image reconstruction. Inverse Probl. 20, 103-120(2008)

3. Combettes, PL: The convex feasibility problem in image recovery. In: Hawkes, P (ed.) Advanced in Imaging and Electron Physcis, vol. 95, pp. 155-270. Academic Press, New York (1996)

4. Chen, JH: Iterations for equilibrium and fixed point problems. J. Nonlinear Funct. Anal. 2013, Article ID 4 (2013)

5. Cho, SY, Qin, X, Kang, SM: Iterative processes for common fixed points of two different families of mappings with applications. J. Glob. Optim. 57, 1429-1446 (2013)

6. Park, S: A review of the KKM theory on $\phi_{A}$-space or GFC-spaces. Adv. Fixed Point Theory 3, 355-382 (2013)

7. Noor, MA, Noor, Kl, Waseem, M: Decomposition method for solving system of linear equations. Eng. Math. Lett. 2, 34-41 (2013)

8. Qin, X, Cho, YJ, Kang, SM: Convergence theorems of common elements for equilibrium problems and fixed point problems in Banach spaces. J. Comput. Appl. Math. 225, 20-30 (2009)

9. Al-Bayati, AY, Al-Kawaz, RZ: A new hybrid WC-FR conjugate gradient-algorithm with modified secant condition for unconstrained optimization. J. Math. Comput. Sci. 2, 937-966 (2012)

10. Cho, SY, Kang, SM: Approximation of common solutions of variational inequalities via strict pseudocontractions. Acta Math. Sci. 32, 1607-1618 (2012)

11. Tanaka, Y: Constructive proof of the existence of Nash equilibrium in a strategic game with sequentially locally non-constant payoff functions. Adv. Fixed Point Theory 2, 398-416 (2012)

12. Kim, JK: Strong convergence theorems by hybrid projection methods for equilibrium problems and fixed point problems of the asymptotically quasi- $\phi$-nonexpansive mappings. Fixed Point Theory Appl. 2011, Article ID 10 (2011)

13. Yang, L, Zhao, F, Kim, JK: Hybrid projection method for generalized mixed equilibrium problem and fixed point problem of infinite family of asymptotically quasi- $\phi$-nonexpansive mappings in Banach spaces. Appl. Math. Comput. 218, 6072-6082 (2012)

14. Qin, X, Cho, SY, Kang, SM: On hybrid projection methods for asymptotically quasi- $\phi$-nonexpansive mappings. Appl. Math. Comput. 215, 3874-3883 (2010)

15. Qin, X, Agarwal, RP, Cho, SY, Kang, SM: Convergence of algorithms for fixed points of generalized asymptotically quasi- $\boldsymbol{\phi}$-nonexpansive mappings with applications. Fixed Point Theory Appl. 2012, 58 (2012) 
16. Qin, X, Agarwal, RP: Shrinking projection methods for a pair of asymptotically quasi- $\boldsymbol{\phi}$-nonexpansive mappings. Numer. Funct. Anal. Optim. 31, 1072-1089 (2010)

17. Chang, SS, Lee, HWJ, Chan, CK, Liu, JA: Strong convergence theorems for countable families of asymptotically relatively nonexpansive mappings with applications. Appl. Math. Comput. 218, 3187-3198 (2011)

18. Chang, SS, Lee, HWJ, Chan, CK, Yang, L: Approximation theorems for total quasi- $\phi$-asymptotically nonexpansive mappings with applications. Appl. Math. Comput. 218, 2921-2931 (2011)

19. Cho, SY, Qin, X, Kang, SM: Hybrid projection algorithms for treating common fixed points of a family of demicontinuous pseudocontractions. Appl. Math. Lett. 25, 854-857 (2012)

20. Li, X, Huang, NJ, Regan, DO: Strong convergence theorems for relatively nonexpansive mappings in Banach spaces with applications. Comput. Math. Appl. 60, 1322-1331 (2010)

21. Cho, SY, Qin, X: On the strong convergence of an iterative process for asymptotically strict pseudocontractions and equilibrium problems. Appl. Math. Comput. 235, 430-438 (2014)

22. Ge, CS: A hybrid algorithm with variable coefficients for asymptotically pseudocontractive mappings in the intermediate sense on unbounded domains. Nonlinear Anal. 75, 2859-2866 (2012)

23. Qin, X, Cho, SY, Kim, JK: Convergence theorems on asymptotically pseudocontractive mappings in the intermediate sense. Fixed Point Theory Appl. 2010, 186874 (2010)

24. Hao, Y: Some results on a modified Mann iterative scheme in a reflexive Banach space. Fixed Point Theory Appl. 2013 $227(2013)$

25. Hao, Y, Cho, SY: Fixed point iterations of a pair of hemirelatively nonexpansive mappings. Fixed Point Theory Appl. 2010, $270150(2010)$

26. Wu, C, Lv, S: Bregman projection methods for zeros of monotone operators. J. Fixed Point Theory 2013, Article ID 7 (2013)

27. Alber, YI: Metric and generalized projection operators in Banach spaces: properties and applications. In: Kartsatos, AG (ed.) Theory and Applications of Nonlinear Operators of Accretive and Monotone Type. Dekker, New York (1996)

28. Agarwal, RP, Cho, YJ, Qin, X: Generalized projection algorithms for nonlinear operators. Numer. Funct. Anal. Optim. 28 1197-1215 (2007)

29. Zhou, H, Gao, G, Tan, B: Convergence theorems of a modified hybrid algorithm for a family of quasi- $\boldsymbol{\phi}$-asymptotically nonexpansive mappings. J. Appl. Math. Comput. 32, 453-464 (2010)

30. Hao, Y: Some weak convergence theorems for a family of asymptotically nonexpansive nonself mappings. Fixed Point Theory Appl. 2010, Article ID 218573 (2010)

31. Qin, X, Huang, S, Wang, T: On the convergence of hybrid projection algorithms for asymptotically quasi-image-nonexpansive mappings. Comput. Math. Appl. 61, 851-859 (2011)

32. Takahashi, W, Zembayashi, K: Strong and weak convergence theorems for equilibrium problems and relatively nonexpansive mappings in Banach spaces. Nonlinear Anal. 70, 45-57 (2009)

33. Qin, X, Cho, SY, Kang, SM: Strong convergence of shrinking projection methods for quasi- $\phi$-nonexpansive mappings and equilibrium problems. J. Comput. Appl. Math. 234, 750-760 (2010)

34. Kim, TH, Xu, HK: Strong convergence of modified Mann iterations for asymptotically nonexpansive mappings and semigroups. Nonlinear Anal. 64, 1140-1152 (2006)

35. Nakajo, K, Takahashi, W: Strong convergence theorems for nonexpansive mappings and nonexpansive semigroups. J. Math. Anal. Appl. 279, 372-379 (2003)

10.1186/1029-242X-2014-221

Cite this article as: Zhang and Wu: Hybrid algorithms for equilibrium and common fixed point problems with applications. Journal of Inequalities and Applications 2014, 2014:221

\section{Submit your manuscript to a SpringerOpen ${ }^{\circ}$ journal and benefit from:}

- Convenient online submission

Rigorous peer review

- Immediate publication on acceptance

- Open access: articles freely available online

- High visibility within the field

- Retaining the copyright to your article 